Anna Belova, Wayne B. Gray, Joshua Linn, Richard D. Morgenstern* and William Pizer

\title{
Estimating the Job Impacts of Environmental Regulation
}

Abstract: In the face of strong policy interest in the possible regulation-jobs linkage and weak analytical evidence to support a generalizable conclusion, what should a regulatory agency like the Environmental Protection Agency do in a regulatory impact analysis (RIA)? Initially, an RIA should start with a clear concept of what the regulatory agency is trying to estimate. Much of the popular debate is looking for a total job effect. Yet one thing we do know is that, in aggregate, there will not be a net job change unless the economy deviates from its normal rate of full employment. The gist of our literature review suggests that looking to historic data for stable statistical relationships between regulatory spending and job changes, even in a single industry, is tenuous at best. However, the intuition is relatively easy to trace out with certain assumptions: (1) added costs imply added activity that entails added jobs; (2) higher product prices or other regulatory limits imply less production that entails fewer jobs. Taking an average employment rate per dollar of relevant economic activity, coupled with an assumed demand elasticity, these effects can be multiplied out into job changes, although such simple calculations must be tested by validating key assumptions or exploring the estimates sensitivity to alternatives. New estimates by Belova, Gray, Linn and Morgenstern [(2013a). Environmental Regulation And Industry Employment: A Reassessment. Center for Economic Studies, U.S. Census Bureau Discussion Paper, CES 1336, July.] indicate that extending and expanding the widely cited approach by Morgenstern, Pizer and Shih [(2002). Jobs Versus the Environment: An Industry-Level Perspective. Journal of Environmental Economics and Management, 43, 412-436] is unlikely to be

Anna Belova: Abt Associates, Inc., 4550 Montgomery Ave \#800N, Bethesda, MD 20814, USA

Wayne B. Gray: Department of Economics, Clark University, 950 Main Street, Worcester, MA 01610, USA

Joshua Linn: Resources for the Future, 1616 P Street, NW, Washington, DC 20036, USA *Corresponding author: Richard D. Morgenstern, Resources for the Future, $1616 \mathrm{P}$ Street, NW, Washington, DC 20036, USA

William Pizer: Sanford School of Public Policy, Duke University, 190 Rubinstein Hall, 302 Towerview Road, Durham, NC 27708, USA

and

Resources for the Future, 1616 P Street, NW, Washington, DC 20036, USA 
successful. Finally, more effort is needed to inform the public about the potential job impacts of new regulations, especially the distinction of these impacts from long-term technological and economic trends.

Keywords: distribution of environmental costs; jobs-environment trade-off.

JEL classifications: C33; D24; J40; Q28.

\section{Introduction}

The labor market effects of environmental regulation have been debated for more than 40 years, although interest has clearly intensified since the beginning of the Great Recession. Although some recent policy pronouncements, including Executive Order (EO) 13563, focus on positive employment effects of new rules, it is well understood that regulation could cause job losses and affect both wages and nonwage compensation in either positive or negative ways. ${ }^{1}$ Despite the strong interest in the issue, conclusive evidence on the labor market impacts of environmental regulation is limited, largely because the impacts of such regulation are difficult to disentangle from long-term technological and economic trends, both domestic and foreign, that affect employment and wages. Meanwhile, the Environmental Protection Agency (EPA), as well as other federal agencies seeking to quantify the effects of their regulations in regulatory impact analyses (RIAs), scramble for answers.

A comprehensive welfare analysis of regulation's impact on labor markets could be organized around a general equilibrium model, including price and quantity effects in both the short and long run, measured in the regulated and unregulated sectors. While such models tend to be highly aggregate in nature and must rely on existing partial equilibrium studies to provide most parameter values, they can incorporate important indirect effects such as the impacts of real wage changes on both labor supply and demand, and the effects of regulation-related improvements

1 Executive Order 12866 (1993) addressed the employment cost of regulation in the requirement that agencies develop an assessment of "any adverse effects on the efficient functioning of the economy, private markets (including productivity, employment, and competitiveness), health, safety, and the natural environment), together with, to the extent feasible, a quantification of those costs." This requirement was clarified in Executive Order 13563 (2011) which stated, "Our regulatory system must promote public health, welfare, safety, and our environment while promoting economic growth, innovation, competitiveness, and job creation." Most recently, in the Draft 2013 Report to Congress on the Benefits and Costs of Federal Regulations and Unfunded Mandates on State, Local, and Tribal Entities (April 2013), the Office of Management and Budget states that "job creation is an important consideration in regulatory review." 
in environmental quality on labor productivity. Such models capture the reemployment of workers in other sectors and can be used to look at aggregate, net job impacts (Graff-Zivin \& Neidell, 2013; Hafstead \& Williams, 2014). Moreover, they provide an automatic metric for social cost, in terms of equivalent or compensation variation in welfare.

In contrast, existing academic studies, mostly partial equilibrium analyses, typically are concerned with the number of jobs gained or lost without accounting for any wage or nonwage compensation price effects. These analyses speak to the practical concern about job changes in regulated industries or regions without focusing on indirect effects, employment changes outside the regulated firms, or welfare or social costs. ${ }^{2}$ Further, the jobs-regulation debate is clouded by definitional issues. For example, some focus on job losses due to environmental regulation separately from job gains in pollution abatement activities. Others examine how the location of domestic production may shift in response to environmental regulation, for example, from counties not attaining federal air quality standards to those in compliance, although these studies generally do not directly measure employment gains in attainment areas. Both labor and trade groups tend to emphasize gross job changes (e.g., job losses in an industry without netting out possible job gains within the same industry) and the cost of rearranging workers within an industry. However, net job loss within a particular industry - which includes all intra-industry employment changes associated with environmental regulation - is also an important metric. An industry-level analysis recognizes that regulated firms relocate employees in other units of the same company, and that plants remaining in the industry often expand output to make up for the reduced production due to exiting or shrinking plants in the same industry, thereby offsetting at least some of the initial job losses.

The present paper reviews a number of industry-level partial equilibrium empirical studies cited in recent policy debates. It also presents results of an updated industry-level analysis using a framework developed by Morgenstern, Pizer and Shih (2002) (hereinafter MPS), which the EPA has relied on extensively in estimating job impacts of new regulations since 2010. The MPS framework is based on a structural analysis, which considered the direct effect of abatement expenditures on employment, the substitution effect associated with the use of other inputs, and the impact of increased costs on the demand for the outputs involved. In the updated analysis, Belova, Gray, Linn and Morgenstern (2013a, BGLM) use the MPS model

2 A notable exception to the exclusive focus on jobs is the recent papers by Walker (2013) and Haveman and Weimer (2015), which are discussed below. There have also been some studies on the general equilibrium employment effects of renewable energy promotion, for example, Böhringer et al. (2012, 2013). 
to estimate employment effects of environmental regulations for additional industries and years, while Belova et al. (2013b) extend the analysis to include the exit of plants in response to environmental regulations.

Our review highlights existing concerns about the potential for spillovers to less regulated plants in the same industry or to facilities in other industries, and the broader labor market impacts, including wages and future employment, which may more accurately reflect true social costs. The present paper also identifies two additional challenges for regulatory agencies in analyzing the labor market impacts of new regulations. First, existing studies are generally based on data from specific industries and regulations, typically from time periods long before the proposed regulation being studied. While EPA has shown considerable care when estimating the benefits from new regulations using benefits transfer analysis, less emphasis has been placed on the estimation of labor market impacts. Second, and perhaps most important, the results of the BGLM analysis suggest great caution in the use of the MPS model for estimating the labor market effects of new environmental regulations. Specifically, using the same methodology and similar data as MPS, BGLM demonstrate that the MPS approach is unlikely to yield reliable estimates of job impacts for industries and time periods other than those considered initially by MPS. While MPS reported job loss estimates of between -0.9 (e.g., a job gain) to 4.6 per million dollars of regulation across 4 industries, BGLM reported job loss estimates of between -1.7 and 31 over a wider set of industries and years. Moreover, they demonstrated these results were also sensitive to specification and estimation assumptions.

Following this brief introduction, Section 2 summarizes several previously published studies on job impacts of federal regulations. Section 3 discusses the challenges for regulatory agencies in estimating labor market impacts of new regulation. Section 4 summarizes the results of the new analyses performed by Belova et al. $(2013 a, b)$. Section 5 offers concluding observations and recommendations.

\section{Review of key partial equilibrium empirical papers on regulation-induced job impacts ${ }^{3}$}

A simple but often ignored point in the regulation-jobs debate is that pollution abatement costs, as measured by the Census Bureau's Pollution Abatement Costs

3 Portions of this section are drawn from Morgenstern (2014) and from Belova, Gray, Linn and Morgenstern (2013a). 
and Expenditures (PACE) survey, represent a relatively small fraction of total manufacturing revenues. Even for the most heavily regulated manufacturers, such as petroleum refining, the share of revenue devoted to pollution abatement costs has not exceeded $2 \%$ over the last 30 years. ${ }^{4}$ Thus, on a prima facie basis it is not obvious that pollution abatement costs should be a major determinant of employment levels.

The industry-level studies on employment impacts of regulations rely on both structural and reduced-form analysis. Structural analysis is generally based on an underlying theoretical model of utility or profit function that is used to derive the estimating equation(s). Reduced-form analyses focusing on the Clean Air Act (CAA), such as those by Henderson (1996), Becker and Henderson (2000), Greenstone (2002), and List et al. (2003), are not explicitly based on a theoretical model. These studies examine the effect of attainment status, with respect to National Ambient Air Quality Standards (NAAQS), on employment growth and other metrics of economic activity. Polluting plants already located in counties that are out of attainment with one or more NAAQS, as well as those facilities seeking to locate in these counties, are likely to face more stringent air pollution control requirements than others. The authors identify the effects of regulation by comparing plants according to whether they are potentially subject to regulation because of nonattainment. ${ }^{5}$ Also using a reduced-form model, Kahn and Mansur (2013) use a border-pair fixed effect model introduced by Holmes (1998) to compare employment by sectors at the county level for adjoining counties that vary by attainment status.

Greenstone (2002) explains the basic logic that underlies the use of the attainment/nonattainment distinction as offering three mechanisms for identifying the effect of regulation. The first is cross-sectional, in which regulations can be interpreted as industry-specific shocks. The second arises over time, as the attainment status of a county changes, leading to potential changes in plant-level responses that can be explored in a pooled analysis. Finally, the nonattainment effects relate only to the plants that emit the pollutant relevant to the definition of

\footnotetext{
4 Reported pollution abatement expenditures were less than $1 \%$ of revenues in the 2005 PACE survey, although questions have been raised about the comparability of that survey to earlier years. While claims that PACE might overstate true costs are more common, an example of potential underestimation is the failure of the PACE survey to include product bans. See Morgenstern, Pizer and Shih (2001) and Gray and Shadbegian (2005) for findings of little or no significant impacts of pollution abatement expenditures on nonabatement activities. See Gray and Shadbegian (1998) for a finding of some adverse impacts in the pulp and paper industry, including both environmental investment crowding out capital investment within a plant, as well as firms shifting investment toward facilities facing less stringent abatement requirements.

5 Ferris and McGartland (2014) discuss several sources of measurement error associated with this measure of regulatory stringency.
} 
attainment status. Thus, the effects of regulation can also be estimated by comparing emitting and nonemitting plants in nonattainment areas.

The reduced-form studies all find some evidence of lower employment growth and investment levels, or that fewer new polluting plants open in nonattainment areas relative to attainment areas. For example, Greenstone (2002) finds that in the first 15 years during which the CAA was in force (1972-87), nonattainment counties lost 590,000 jobs, $\$ 37$ billion in capital stock, and $\$ 75$ billion (1987 dollars) of output in pollution-intensive industries, relative to those counties which were in attainment with the CAA requirements.

All of the studies of employment effects noted so far estimate job effects without attempting to value them in terms of economic cost or welfare. Walker (2013) makes an important contribution to this literature by focusing on workers rather than plants as the unit of analysis, which permits estimation of actual costs related to regulatory job loss. Specifically, he relies on linked worker-firm data to study the impact of the 1990 CAA Amendments on several labor market outcomes that were not examined previously, including nonemployment (i.e., unemployment and reduced labor force participation) and long run earnings losses from regulationinduced job transitions. In addition to plant location in a nonattainment area, Walker (2013) identifies regulatory effects using information on emissions and permitting status of individual plants under the 1990 CAA Amendments - a refinement compared to other reduced-form analyses. The study finds that workers in the affected plants experienced over $\$ 5.4$ billion in (aggregate) foregone earnings and that five years after the regulatory changes there was a $10 \%$ decline in employment relative to 1990 levels (or a $15 \%$ decline relative to the counterfactual employment estimate for 1995).

Forgone earnings are still not exactly the same as social cost or welfare, which will depend on an individual's reservation wage or opportunity cost of leisure. A recent paper by Haveman and Weimer (2015) estimates the difference between lost earnings and social costs in a partial equilibrium context. They label this difference the 'scarring' effect and suggest it is quite substantial, especially at times of high unemployment.

Although the results from these reduced-form analyses indicate a shift of economic activity from nonattainment to attainment counties, they do not conclusively demonstrate that there is an overall decline in aggregate employment or economic activity due to environmental regulation. For example, plants in a county that changes from attainment to nonattainment for a particular NAAQS between one time period and the next could reduce employment, while plants in an attainment county increase employment. Thus, it is likely that some or all of the 590,000 individuals in the Greenstone analysis who lost jobs in the nonattain- 
ment areas found work elsewhere, and some or all of the capital and output losses were undoubtedly offset, at least in part, by increases elsewhere in the country. The reduced-form analyses, however, are unable to provide estimates of such effects, because these benefits arise at plants and locations that are not directly affected by regulation. Furthermore, the costs associated with spatial reallocation of production or earnings losses as a potential consequence of regulation, are not typically considered in national-level benefit cost analyses. Even if they were to be included, the results from studies relying on a retrospective assessment of a specific regulatory change (e.g., the 1990 CAA Amendments) cannot be scaled in any obvious way for application in RIAs for new and potentially different regulations.

Two widely cited papers that present a formal structural model of the underlying profit maximizing/cost minimizing activities of the firm are Berman and Bui (2001) and MPS. Berman and Bui (2001) estimate the employment impacts of ozone and NOx regulations in California's South Coast Air Quality Management District, from 1979 to 1992 , a period when some of the nation's most stringent air quality regulations were put in place. ${ }^{6}$ Their model allows environmental regulation to operate via two mechanisms: (1) the output elasticity of labor demand, and (2) the effect of pollution abatement activities on demand for labor and other variable factors of production. Importantly, using this model they demonstrate that the net effect of environmental regulation on employment is ambiguous on theoretical grounds. Based on their empirical analysis, however, the authors find that "while regulations do impose large costs, they have a limited effect on employment." They conclude that local air quality regulation "probably increased labor demand slightly" but that "the employment effects of both compliance and increased stringency are fairly precisely estimated zeros, even when exit and dissuaded entry effects are included." Berman and Bui suggest that the limited effects likely arose because (1) the regulations applied disproportionately to capital-intensive plants with relatively little employment; (2) the plants sold to local markets where competitors were subject to the same regulations (so that sales were relatively unaffected); and (3) abatement inputs served as complements to employment.

Recognizing the potential for environmental regulations to lead to both a rearrangement of production activities and a potential output contraction, MPS developed a structural model to estimate the relationship between regulatory costs and output. Namely, the model considered the relationship between demand, unit cost, and the labor component of cost:

$$
\text { employment }=\frac{\text { demand }(\text { unit cost }) \times \text { unit cost } \times \text { labor share }}{\text { wage }}
$$

6 Like the reduced-form models tied to specific regulatory events, it is not clear how the Berman and Bui study could be used in the analysis of a new, unrelated regulation. 
As regulations change, this model enables a decomposition of the employment effects into the cost, factor shift, and demand components:

(a) Cost effect: As production costs increase from added pollution abatement activities, plants use more of all inputs (including labor) to produce the same level of output. The cost effect depends on the relationship between regulatory costs and total production costs. In principle, the cost effect should be positive, meaning that an increase in regulatory stringency causes employment to increase;

(b) Factor shift effect: Postregulation production technologies may be more or less labor intensive (i.e., more or less labor may be required per dollar of output). The factor shift effect depends on whether regulatory costs induce substitution toward or away from labor while holding total costs constant, so the factor shift effect could be either positive or negative;

(c) Demand effect: Higher production costs raise market prices, thereby reducing consumption (and production) as well as demand for labor within the regulated industry.

As MPS emphasize, the public debate focuses mostly on the demand effect. However, this ignores the fact that employment could grow if the cost effect is sufficiently large or if production becomes more labor intensive. Disentangling the three effects can help clarify the relationship between regulation and employment.

To estimate these two effects MPS develop a plant-level translog cost function that includes regulatory costs as well as the costs of four productive inputs: capital, labor, energy, and materials. They show that the cost and factor shift effects depend on the cost function parameters and input cost shares. Assuming monopolistic competition among plants in an industry, MPS show that the demand effect depends on the elasticity of total industry output demand with respect to the output price. When demand for industry output is more elastic, increases in costs reduce total industry output and, thus, employment.

Like Berman and Bui, MPS demonstrate that the net impact of regulation on employment is ambiguous in theory. Using a six-year (noncontinuous) panel data set, covering the period 1979-91, MPS fit their model using data from four highly polluting/regulated industries (petroleum refining, plastics, pulp and paper, and iron and steel). Regulatory burden is measured by the self-reported PACE data. Focusing on within-plant variation over time, they are able to account for the differences in a plant's ability to adapt their production processes to stricter environmental requirements. To calculate the effect of demand changes on employment, MPS estimate demand elasticities using industry-level output and productivity data.

The MPS estimate of the cross-industry average impact of a one million dollar increase in abatement expenditures is an addition of 1.55 jobs, and this effect is not 
statistically different from zero. There are, however, positive and significant effects for plants in both the plastics and petroleum sectors, when they are considered individually. Importantly, the paper highlights the cross-industry average effect, not the individual industry results, and emphasizes the lack of statistical significance of this result.

It is useful to consider some of the key differences between the studies that used reduced-form analysis and those based on structural analysis:

- The universe of included facilities differs across studies. All the reduced-form analyses are based on estimates derived from the entire manufacturing sector and the results represent cross-industry averages. In contrast, both Berman and Bui and MPS focus on a small number of individual industries, defined at the 6-digit NAICS level, and only focus on net changes in those industries.

- The regulatory burdens are represented by different, yet imperfect, proxies. The reduced-form studies rely on county NAAQS nonattainment designations in combination with information on either industry- or plant-specific emissions of air pollutants. Berman and Bui (2001) focus on detailed regulatory requirements that are measured on a plant-specific basis. MPS uses total abatement expenditures across all media to represent regulatory burden.

- Misspecification is a potential issue for both the structural and the reducedform models. While reduced-form analyses rely on a number of statistical assumptions, structural analyses also require a theoretical framework for making inferences. There could be more room for misspecification in structural analyses, because these theoretical models may be a poor approximation of the actual firm-level decision process. However, the structural analyses do employ fairly standard theory.

- As Masur and Posner (2012) suggest, it is also likely that environmental regulators aim to minimize adverse employment impacts when crafting new rules. While this could, in principle, explain the findings of the structural models for specific industries, it seems unlikely that an agency could consistently produce such results in the absence of any credible analysis of the impacts.

Neither the structural nor the reduced-form analyses account for the complexities of environmental rulemaking and implementation practices. Regulatory requirements vary significantly by pollutant, medium, and industry, and are not simply an on/off switch captured by the attainment designations. Pollution abatement costs, as reported in the PACE survey, include a variety of activities, not all driven by regulatory pressure. Sheriff, Ferris and Shadbegian (2015) consider more detailed regulatory classifications for the case of ozone, where there are six different nonattainment categories affecting fossil electric generating plants. Overall, 
they find the treatment effect is remarkably heterogeneous across production units included in prior studies.

Notwithstanding any of the possible explanations for the differences between the reduced-form and structural analyses, we do not see convincing evidence of significant net job losses attributable to environmental regulations from the plantlevel partial equilibrium studies reviewed thus far. Walker (2013) provides valuable evidence on broader labor market impacts on wages and future employment for affected workers, although those impacts have not generally been considered in RIAs.

\section{Use of the results from partial equilibrium studies in regulatory impact analyses (RIAs)}

We now turn to the issue of applying modeling results, such as those reported by MPS, in RIAs for new environmental rules. Modeling results such as MPS - in contrast to most of the other models and studies - are potentially well suited to application in RIAs because they explicitly look at jobs and relate them to a cost measure that is already included in most RIAs. The application of analytical results from one context to other, less studied, context is fairly routine. For example, many regulatory analyses rely on a benefits transfer to value environmental damages. Yet, the variety in the estimated job impact metrics (e.g., gross vs. net impact) as well as the variation in the direction/magnitude of the estimated impacts raises important questions about feasibility of making extrapolations from the literature.

In a recent analysis of EPA practices in estimating job impacts of new regulations in RIAs, Smith, Gans and Yuan (2013) reviewed 57 major rules issued by the EPA's Office of Air and Radiation over the period 1997-2011. Of those 57 RIAs, almost one third developed quantitative job impact estimates. Seven of the nine 2011 RIAs contained such estimates, with four of the seven showing net jobs gained based strictly on MPS. Interestingly, most of the job estimates generated pre-2010, which rely on other methods, find negligible employment impacts or job losses.

Methodologically, the EPA treatment of the MPS results in RIAs raises a number of concerns. Specifically, the EPA has estimated employment effects by scaling up the MPS cross-industry estimate of 1.55 jobs gained per million dollars in pollution abatement expenditures by the expected cost of the regulation, without regard to the nature of the new rule, the industries affected, or the baseline changes in industry structure/activity that might have occurred since the 1979-91 period stud- 
ied by MPS. ${ }^{7}$ While standard errors were calculated in most cases, the summary characterizations often downplay or ignore the confidence intervals straddling zero and focus strictly on the (positive) point estimates.

\section{New analyses by Belova, Gray, Linn and Morgenstern $(2013 a, b)$}

BGLM address at least some of these concerns by extending the MPS time period to include the most recently available data, and by expanding the industries covered beyond the original four to a total of ten manufacturing industries. Aside from expanding the set of industries and time periods, BGLM adopt the same methodology as MPS. Further, BGLM compare their results using the identical MPS methodology with a reduced-form model that relaxes many of the structural assumptions, but does not permit the decomposition into the three effects discussed above. The companion paper, Belova et al. (2013b), takes a first step at introducing dynamics by examining the potential effects of changes in PACE expenditures on the industry exit probabilities for individual firms.

BGLM choose an initial set of industries for analysis based on pollution abatement expenditures and then screen them according to the expected sample sizes in the Census data. Informal consultations with technical experts were also used to assess the likely degree of homogeneity of production functions within the selected industries. ${ }^{8}$ The BGLM panel includes all of the years in the MPS time span (1979 to 1991 , omitting only 1983 and 1987, when PACE survey was not available) plus 1976-78, 1992-94, 1999, and 2005. As in MPS, the initial focus in the update was on nonexiting plants.

With the expanded data, BGLM attempt to replicate the MPS modeling approach, except for the method used to estimate the industry-specific demand elasticities. The own-price elasticity of industry demand, reflecting the change in total industry output given a change in the average price of output, is an important parameter in the MPS model. It is used to simulate the effect of PACE expenditure on industry-level employment. The larger the elasticity (in absolute value), the more industry output falls when PACE expenditure increase, and the larger the

7 Regarding the cross-industry differences reported by MPS for the four principal industries, the EPA ignored even larger differences between those four and a group of six additional industries examined at the time of the original analysis for which the authors were unable to develop credible cost function estimates (MPS 2001).

8 The added industries are: Portland cement, rolling and drawing, pipe fitting, miscellaneous wood products, pharmaceuticals, and other electrical equipment. 
demand effect. ${ }^{9}$ Like MPS, BGLM estimate the industry demand elasticity using industry-level variables, but implement a more direct approach to estimating the demand elasticity and attempt to account for the potential endogeneity of industry prices. ${ }^{10}$

The BGLM results differ considerably from MPS. For the four original industries, the estimate effects in BGLM are uniformly larger than those in the earlier paper, even after accounting for the new estimates of demand elasticities and the different normalizing year for measuring the expenditures. ${ }^{11}$ Of the six newly added industries, only the rolling and drawing industry yields a significant effect, and that is also positive and large. Like MPS, BGLM did not find any evidence of large negative effects. For several industries and time periods, the large positive estimates are driven principally by the cost effects. The magnitude of the cost effects seems to imply that nearly all of the regulatory expenditure was used to hire workers, which seems implausible because of the capital intensity of pollution abatement in these industries.

After reporting the main results, BGLM describe extensive additional analysis trying to explain the large positive estimated employment effects and the differences in results relative to MPS. One possibility is that the methodology is sensitive to the structural model used, but in some cases BGLM also obtained similarly implausible results using a reduced-form model estimated on similar data. Alternatively, there may have been problems arising from an omitted variables bias or potential endogeneity of the PACE variables that happened to be more severe in the BGLM samples, compared to the MPS samples. However, BGLM were not able to identify suitable instrumental variables or alternative strategies to address either possibility. Other potential factors explored by the authors include differences in the construction of the variables, estimation samples, and software used in the two studies. Also explored were the possible sensitivity of the translog cost function to the estimation sample and the heterogeneity of the cost function. In examining these possibilities, only two explanations were not rejected: heterogeneity of the cost function and omitted variables/endogeneity of PACE.

\footnotetext{
9 The industry demand elasticity is distinct from a plant's demand elasticity. The latter is typically estimated using variation in output prices and output across plants. The elasticity thus reflects the change in demand for a plant's output given a change in its price relative to the prices of all other plants in the industry. The industry demand elasticity should be smaller in magnitude (less elastic) than the plantlevel demand elasticity because it corresponds to the reduction in total industry output if all plant output prices increase by the same amount.

10 This approach is different from estimating plant elasticities using plant-level variables. The plantspecific elasticity estimation is more common in the current literature (e.g., see Foster, Haltiwanger \& Syverson, 2008).

11 The numerical values in their summary of the original estimates are different because they report the results for one million 1997 dollars. They are rescaled to be consistent with the new estimates.
} 
A key limitation of the MPS paper is the exclusive focus on continuing plants. Relying on a balanced panel implied the exclusion of plants that exited the industry during the study period, thereby precluding analysis of the potential impact of regulation on exit. Yet, environmental regulation could affect both plant entry and exit, for example, causing plants to leave industries with more stringent regulation or other plants to enter industries with less stringent regulation. Because the industries studied are mostly contracting rather than expanding, Belova et al. (2013b) focus on the effect of regulation on plant exit, implementing a reduced-form approach that links regulatory costs and exit probabilities. Perhaps unsurprisingly, they found a quite limited impact of regulation on plant exit, with mostly small and insignificant effects, including decreases as well as increases in exit probabilities associated with higher pollution abatement expenditures across the various industries.

Regarding the utility of MPS-style modeling results for estimating job impacts in the RIA context, BGLM recommend that EPA refrain from using these results until the underlying cause(s) for the implausibly large estimates in the employment effects found in Belova et al. (2013a) are uncovered and resolved.

\section{Conclusions and recommendations}

In the face of strong policy interest in the possible regulation-jobs linkage and weak analytical evidence to support a generalizable conclusion, what should a regulatory agency like the EPA do? While partisans will inevitably pick studies to support their own views, an RIA developed by a public agency must aim for a higher standard.

First, an RIA should start with a clear concept of what the regulatory agency is trying to estimate. Much of the popular debate is looking for a total job effect. Yet one thing we do know is that, in aggregate, there will not be a net job change unless the economy is deviating from its normal rate of full employment. Lost jobs will give way to created jobs, and vice versa. There is a cost to this reshuffling, as highlighted by Walker (2013). However, if estimates of job gains and losses are going to be part of an RIA, the appropriate scope for a jobs calculation needs to be defined more precisely.

In their partial equilibrium model, MPS focus strictly on the industry being regulated - and how regulation could cause more employment in that industry in order to comply with the regulation or less employment as demand shifted away from the regulated industry. Yet, it is by no means obvious that any job losses or gains related to industry-specific job impacts will reflect the net job impacts. Thus, an RIA might also want to consider a general equilibrium approach, looking upstream, to key suppliers, laterally, to domestic industries where the regulated industry's lost demand 
might increase, or at temporary job creation as new investment occurs (a capitalized variant of the MPS cost effect). For example, a recent paper by Hafstead and Williams (2014) found that more than 50\% of the jobs lost in the regulated industry were offset by employment gains elsewhere.

Second, the simplest approach may be best. The gist of our literature review suggests that looking to historic data for stable statistical relationships between regulatory spending and job changes, even in a single industry, is tenuous at best. However, the intuition of at least two of the MPS effects is relatively easy to trace out with certain assumptions: (1) added costs imply added activity that entails added jobs; (2) higher product prices or other regulatory limits imply less production that entails fewer jobs. Taking an average employment rate per dollar of relevant economic activity, coupled with an assumed demand elasticity, these effects can be multiplied out into job changes. This can be extended, as suggested above, to associated upstream activities or substitutes for reduced demand. Interestingly, the EPA seems to have adopted this type of intuitive approach in the recent analysis of the $111(\mathrm{~d})$ rule. $^{12}$

Third, such simple calculations must be tested by validating key assumptions or exploring the estimates' sensitivity to alternatives. For example, average employment impacts in a given industry may differ geographically, as output changes may vary across the country. Smith et al. (2013) reports on a symposium examining the employment effects of environmental regulation, concluding that the adjustments that will occur in a given labor market will depend on local economic conditions. Thus, accurately assessing the overall employment effects from a given regulation may require a more careful treatment of the spatial distribution of regulatory impacts, and the employment effects may change as economic conditions change.

Further, EPA could seek to improve this methodology. The BGLM findings indicate that extending and expanding the original MPS approach is unlikely to be successful. However, new research might look for other ways to relate regulatory impacts to job outcomes. The key is to support a methodology that can be applied to prospective regulatory impact assessments, not just retrospective quasiexperiments, and that can predict the impact of the regulation against a true "no regulation" baseline, not a potentially affected control group. Even when the economy is at full employment, the labor market impacts of regulation are likely to remain part of public debates. Thus, it is incumbent on regulatory agencies to conduct or help support independent research on the topic, including both partial and general equilibrium approaches.

12 Without endorsing the specifics of the 111 (d) RIA, we simply note that the agency has explicitly considered the employment impacts of both the added costs associated with the new regulatory activities and of the reduced production associated with higher product prices. 
Finally, more effort is needed to inform the public about the potential job impacts of new regulations. As noted, regulations can have many different impacts on labor markets, some positive, some negative. Distinguishing these impacts from long-term technological and economic trends, both foreign and domestic is a daunting task for experts in the field. Thus it is no surprise that discussions in the media often confuse gross versus net effects, job loss versus true social costs, and other impacts. While there is no simple remedy to this problem, we believe public agencies have a responsibility to present a clear and concise discussion of the limitations of any estimates of job impacts they develop. Absent such discussion, the public debate will be forced to rely even more on stakeholder claims that may be unreasonable and/or polarizing, thereby increasing the confusion in the public's mind about this complex issue.

\section{References}

Becker, Randy A. \& Henderson, J. Vernon (2000). Effects of Air Quality Regulations on Polluting Industries. Journal of Political Economy, 108(2), 379-421.

Belova, Anna, Gray, Wayne B., Linn, Joshua \& Morgenstern, Richard D. (2013a). Environmental regulation and industry employment: a reassessment. Center for Economic Studies, U.S. Census Bureau Discussion Paper, CES 13-36, July.

Belova, Anna, Gray, Wayne B., Linn, Joshua \& Morgenstern, Richard D. (2013b). Environmental regulation and manufacturing plant exit: a preliminary analysis. Unpublished paper, July.

Berman, Eli \& Bui, Linda T. (2001). Environmental Regulation and Labor Demand: Evidence from the South Coast Air Basin. Journal of Public Economics, 79(2), 265-295.

Ferris, Ann \& McGartland, Albert (2014). A Research Agenda for Improving the Treatment of Employment Impacts in Regulatory Impact Analysis. In Cary Coglianese, Adam Finkel \& Chris Carrigan (Eds.), Does Regulation Kill Jobs? ( Chapter 9, pp. 170-189). Philadelphia: University of Pennsylvania Press.

Foster, Lucia, Haltiwanger, John \& Syverson, Chad (2008). Reallocation, Firm Turnover, and Efficiency: Selection on Productivity or Profitability? American Economic Review, 98(1), 394-425.

Graff-Zivin, Joshua \& Neidell, Matthew (2013). Environment, health, and human capital. Journal of Economic Literature, 51(3), 689-730.

Gray, W. B. \& Shadbegian, R. J. (1998). Environmental regulation, investment timing, and technology choice. The Journal of Industrial Economics, 46(2), 235-256.

Gray, W. B. \& Shadbegian, R. J. (2005). When and why do plants comply? Paper mills in the 1980s*. Law \& Policy, 27(2), 238-261.

Greenstone, Michael (2002). The Impacts of Environmental Regulations on Industrial Activity: Evidence from the 1970 and 1977 Clean Air Act Amendments and the Census of Manufactures. Journal of Political Economy, 110(6), 175-1219. 
Greenstone, M., List, J. A. \& Syverson, C. (2012). The effects of environmental regulation on the competitiveness of US manufacturing. National Bureau of Economic Research Paper No. w18392. See https://scholar.google.com/scholar?cluster=159254372036423 06034\&hl=en\&as_sdt=0,9.

Hafstead, Marc A. C. \& Williams, Roberton C., III (2014). Unemployment and environmental regulation in general equilibrium. Resources for the Future, Discussion Paper.

Haveman, Robert H. \& Weimer, David L. (2015). Public Policy Induced Changes in Employment: Valuation Issues for Benefit-Cost Analysis. Journal of Benefit Cost Analysis, forthcoming.

Henderson, J. Vernon (1996). Effects of Air Quality Regulation. American Economic Review, 86(4), 789-813.

Holmes, Thomas (1998). The Effects of State Policies on the Location of Industry: Evidence from State Borders. Journal of Political Economy, 106(4), 667-705.

Kahn, Mathew E. \& Mansur, Erin T. (2013). Do Local Energy Prices and Regulations Affect the Geographic Concentration of Employment? Journal of Public Economics, 101, 105-114.

Kahn, M. E. \& Mansur, E. T. (2010). How do energy prices, and labor and environmental regulations affect local manufacturing employment dynamics? A regression discontinuity approach. National Bureau of Economic Research Paper No. w16538.

List, John A., Millimet, Daniel L., Fredriksson, Per G. \& McHone, W. Warren (2003). Effects of environmental regulations on manufacturing plant births: Evidence from a propensity score matching estimator. Review of Economics and Statistics, 85(4), 944-952.

Masur, Jonathan S. \& Posner, Eric A. (2012). Regulation, Unemployment, and Cost-Benefit Analysis. Virginia Law Review, 98, 579.

Morgenstern, R. D. (2014). Analyzing the employment impacts of regulation. In C. Coglianese, A. M. Finkel \& C. Carrigan (Eds.), Does regulation kill jobs? (pp. 33-50). Philadelphia, PA: University of Pennsylvania Press.

Morgenstern, Richard D., Pizer, William A. \& Shih, Jhih-Shang (2001). The Cost of Environmental Protection. Review of Economics and Statistics, 83(4), 732-738 (An RFF Discussion Paper version from 1998 providing more information, including a discussion of the seven smaller industries, is available at: http://www.rff.org/RFF/Doc uments/RFF-DP-98-36.pdf).

Morgenstern, Richard D., Pizer, William A. \& Shih, Jhih-Shang (2002). Jobs Versus the Environment: An Industry-Level Perspective. Journal of Environmental Economics and Management, 43, 412-436.

Sheriff, Glenn, Ferris, Ann \& Shadbegian, Ronald (2015). How did air quality standards affect employment and generation at U.S. power plants? The importance of stringency, implementation, and timing. EPA Working Paper (National Center for Environmental Economics).

Smith, Anne E., Gans, Will \& Yuan, Mei (2013). Estimating employment impacts of regulations: a review of EPA's methods for its air rules. NERA Economic Consulting, February.

Walker, W. Reed (2013). The Transitional Costs of Sectoral Reallocation: Evidence from the Clean Air Act and the Workforce. Quarterly Journal of Economics, 128(4), 1787-1836. 